\title{
Keep the quality high: the benefits of lot testing for the quality control of malaria rapid diagnostic tests
}

\author{
Sandra Incardona ${ }^{1 *} \mathbb{0}$, David Bell ${ }^{2}$, Ana Campillo ${ }^{1}$, Jane Cunningham³ ${ }^{3}$, Frederic Ariey ${ }^{4}$, Thierry Fandeur ${ }^{5}$, \\ Jennifer Luchavez ${ }^{6}$, Christian Anthony Luna ${ }^{6}$, Didier Ménard7', Sina Nhem ${ }^{8}$, Johanna Beulah Sornillo 9 , \\ Benoit Witkowski ${ }^{10}$, Zachary Katz ${ }^{1}$, Sabine Dittrich ${ }^{1,11+}$ and Xavier C. Ding ${ }^{1 \dagger}$
}

\begin{abstract}
Background: The production and use of malaria rapid diagnostic tests (RDTs) has risen dramatically over the past 20 years. In view of weak or non-existing in vitro diagnostics (IVD) regulations and post-marketing surveillance (PMS) systems in malaria endemic countries, the World Health Organization, later joined by the Foundation for Innovative New Diagnostics, established an independent, centralized performance evaluation and Lot Testing (LT) programme to safeguard against poor quality of RDTs being distributed through the public health sector of malaria endemic countries. RDT performances and manufacturer quality management systems have evolved over the past decade raising questions about the future need for a centralized LT programme.

Results: Between 2007 and 2017, 6056 lots have been evaluated, representing approximately 1.6 Billion RDTs. A total of 69 lots (1.1\%) failed the quality control. Of these failures, 26 were detected at receipt of the RDT lot in the LT laboratory, representing an estimated 7.9 million poor quality RDTs, and LT requesters were advised that RDTs were not of sufficient quality for use in patient management. Forty-three were detected after long-term storage in the laboratory, of which 24 (56\%) were found to be due to a major issue with insufficient buffer volume in single use buffer vials, others predominantly showing loss of sensitivity. The annual cost of running the programme, based on expenses recorded in years 2014-2016, an estimated volume of 700 lots per year and including replenishment of quality control samples, was estimated at US\$178,500 (\$US 255 per lot tested).

Conclusions: Despite the clear benefits of the centralized LT programme and its low cost compared with the potential costs of each country establishing its own PMS system for RDTs, funding concerns have made its future beyond 2020 uncertain. In order to manage the risks of misdiagnosis due to low quality RDTs, and to ensure the continued safety and reliability of malaria case management, there is a need to ensure that an effective and implementable approach to RDT quality control continues to be available to programmes in endemic countries.
\end{abstract}

Keywords: Malaria, Diagnostics, Rapid diagnostic test, Lot testing, Quality control, Post-market surveillance

*Correspondence: sandra.incardona@finddx.org

tSabine Dittrich, Xavier C. Ding contributed equally to this work

${ }^{1}$ FIND, Geneva, Switzerland

Full list of author information is available at the end of the article

\section{Background}

As RDTs became increasingly used in the early 2000s, critical quality limitations became apparent [1-3] which could not be identified and resolved by the weak regulatory oversight in endemic countries. To respond to this need for an independent quality control (QC) system, the World Health Organization (WHO), together with

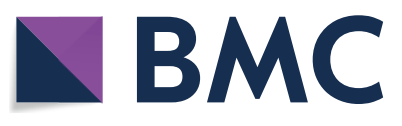

c) The Author(s) 2020. This article is licensed under a Creative Commons Attribution 4.0 International License, which permits use, sharing, adaptation, distribution and reproduction in any medium or format, as long as you give appropriate credit to the original author(s) and the source, provide a link to the Creative Commons licence, and indicate if changes were made. The images or other third party material in this article are included in the article's Creative Commons licence, unless indicated otherwise in a credit line to the material. If material is not included in the article's Creative Commons licence and your intended use is not permitted by statutory regulation or exceeds the permitted use, you will need to obtain permission directly from the copyright holder. To view a copy of this licence, visit http://creativeco mmons.org/licenses/by/4.0/. The Creative Commons Public Domain Dedication waiver (http://creativecommons.org/publicdomain/ zero/1.0/) applies to the data made available in this article, unless otherwise stated in a credit line to the data. 
the Research Institute for Tropical Medicine, Philippines, and the Institut Pasteur du Cambodge, Cambodia, initiated a lot-testing (LT) programme in 2003, which then expanded in collaboration with the Foundation for Innovative New Diagnostics (FIND) to a Global RDT Evaluation Programme, comprising the Product Testing and LT programmes $[4,5]$. The former informed WHO procurement criteria until RDT prequalification became a requirement in December 2017. LT assesses lot quality before deployment at the request of procurers, manufacturers, or National Malaria Control Programmes (NMCPs), using a testing algorithm with standardized QC samples derived from patient blood [6] (Fig. 1).

Within a few years, LT has become a component of the procurement processes of all major public sector procurers, including Médecins Sans Frontières (MSF), the United States President's Malaria Initiative (PMI), and the United Nations International Children's Emergency Fund (UNICEF), and it became mandatory for procurement under grants from the Global Fund (GF). When the funding of the UNITAID programme ended in 2017, the WHO leveraged funding to support one laboratory, but stopped replenishing QC sample stocks and the future of the programme is now unclear [7]. Since mid-2017, the GF ceased to require WHO-coordinated LT, requesting instead that countries "arrange for the monitoring of the quality of diagnostic products procured with grant funds in line with relevant WHO guidelines on post-marketing surveillance (PMS) of in vitro diagnostics (IVDs)" [8]. Precise guidance on testing procedures and QC standards is however not available, except some example procedures for LT of HIV RDTs [9]. Other procurers continue to utilize the service.

\section{Impact of the lot-testing programme}

From 2007 to 2017, 6056 lots were evaluated, representing an estimated 1.6 billion RDTs [10] (unpublished LT programme data). Overall, 69 (1.1\%) failures were detected, of which 26 at RDT receipt and 43 after long-term storage (Table 1). The 26 initial failures correspond to an estimated 7.9 million RDTs, which could have reached end-users and potentially led to incorrect clinical decisions. Most failures (20/26, 76.9\%) were due to non-detection of Plasmodium vivax samples at 200 parasites $/ \mu \mathrm{L}$, and failure rates did not change much over time, demonstrating the importance of continued testing.

More than half of the long-term failures $(24 / 43,56 \%)$ were due to partly evaporated buffer in single-use buffer vials [10-12]. Throughout 2014 to June 2017, this problem affected 24 lots of 5 products from $3 \mathrm{WHO}$-prequalified manufacturers. The detection of this issue triggered a WHO Notice of Concern discouraging procurement of these products until problem resolution [13]. Without LT, such issues may go undetected, as proactive post-marketing surveillance (PMS) for diagnostics is weak and health workers are usually not trained to detect and report quality issues, often being unaware of existing complaint systems $[14,15]$. The programme's formal reporting of RDT anomalies, such as incomplete clearing and red background [16], also formed the basis for successful product replacement in some cases. The 'non-routine' LT assessed RDTs withdrawn from the field in various countries and allowed differentiating between product defects, operator errors, and parasite factors. Ruling out product defects led to the subsequent confirmation of high Plasmodium falciparum hrp $2 / h r p 3$ gene deletion rates in Eritrea as the cause of false negative RDT results [17], impacting on the use of HRP2-based RDTs in this region.

There is a high probability that the LT programme has also impacted on RDT quality through the pressure placed on manufacturers to meet LT quality standards for all lots sold in the public sector, and/or through the potential publicity associated with failure. A lot failure typically leads to lot replacement and is associated with financial and reputational costs for manufacturers. In a survey conducted in 2014,31\% (11/35) of manufacturers indicated that the LT Programme had triggered improvements of their lot-release procedures or QC panel characteristics [18].

\section{The future of $\mathrm{LT}$}

These findings demonstrate important contributions of the LT programme detecting defects even in WHO prequalified products. Other existing processes verifying RDT quality cannot fully substitute for such an independent programme. While manufacturers have their own lot-release procedures, assessed by the WHO prequalification of diagnostics (PQ) process [19], there is no

(See figure on next page.)

Fig. 1 Overview of the Lot Testing process. a Schematic overview of the overall lot testing process, based on samples at 200 parasites per microlitre of blood $(\mathrm{p} / \mathrm{\mu L}$ ) and with antigen concentrations within a standardized range corresponding to this parasitaemia, *indicates a condition that applies to combination tests only. $\mathbf{b}$ Schematic overview of the testing procedure and pass/fail criteria. RDTs must detect all repeats of all samples at $200 \mathrm{p} /$ $\mu \mathrm{L}$ in order to pass. False positives and anomalies, such as red background, flow failure, etc., are reported as comments and not used for pass/fail decisions. Insufficient buffer is reported as a "fail" result, "confirmatory testing in a second laboratory, if necessary, is performed according to the same two-step procedure than for the initial testing and using a different set of samples. c Main components and activities required for the LT programme are indicated. $\mathrm{LT}=\mathrm{L}$ ot Testing, $\mathrm{Pf}=$ P. falciparum, $\mathrm{EQA}=$ External quality assessment, $\mathrm{QMS}=$ Quality management system 
a

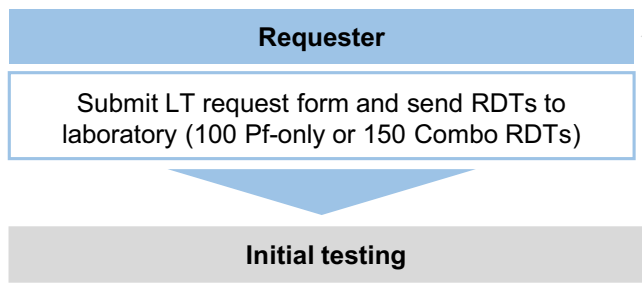

- 4 P. falciparum and 4 P. vivax* samples at 200 $\mathrm{p} / \mu \mathrm{L}$, tested each in sextuplicate

- 10 negative specimens, tested each in simplicate

- Confirmatory testing in $2^{\text {nd }}$ laboratory in case of failure (same procedure)

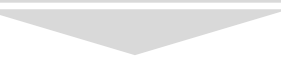

\section{Long-term testing}

Storage at $37^{\circ} \mathrm{C}$ until 6 months before expiry

- 2 P. falciparum and 2 P. vivax* samples at 200 $\mathrm{p} / \mu \mathrm{L}$, tested each in sextuplicate

- 2 negative specimens, tested each in simplicate

- Confirmatory testing in $2^{\text {nd }}$ laboratory in case of failure (same procedure) b

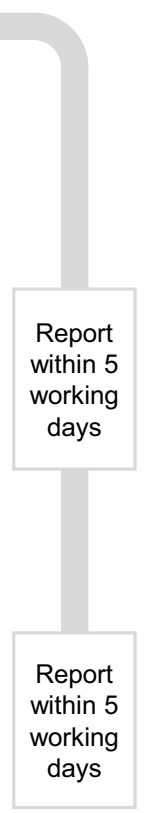

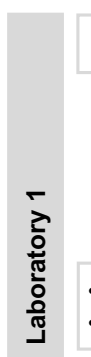

Testing with selected samples

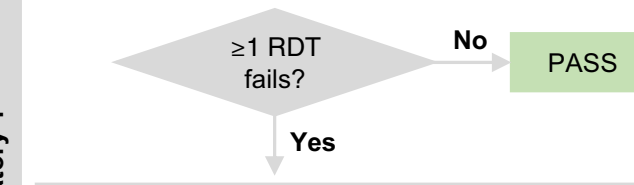

- Validate failed sample(s) with reference RDTs

- Substitute failed sample(s) for repeat testing

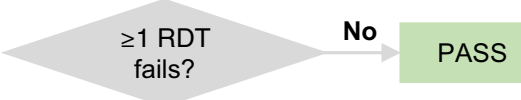

Yes

Send RDTs for confirmatory testing

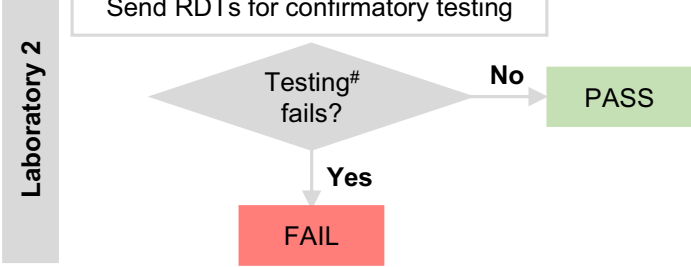

C

Programme steering committee

Annual review of the programme performance

- Review of procedures and validation of changes

\section{- Technical oversight and coordination \\ - Contracting of partner laboratories \\ - Database management}

\section{QMS}

\section{Sample collection with partner institutions}

- Ethics approval

- Patient enrollment and sample collection

- Sample dilution to $200 \mathrm{p} / \mu \mathrm{L}$ and within acceptable antigen concentration ranges

- Freezing of diluted sample aliquots at $70^{\circ} \mathrm{C}$

\section{Samples and data}

\section{QMS}

\section{Sample characterization with} partner laboratories

- Plasmodium spp. typing by PCR

- Antigen quantification by ELISA

- Data management and verification

\section{Programme coordinator}

- Online publication of programme results

- Management of programme funding

- Management of communication with requesters

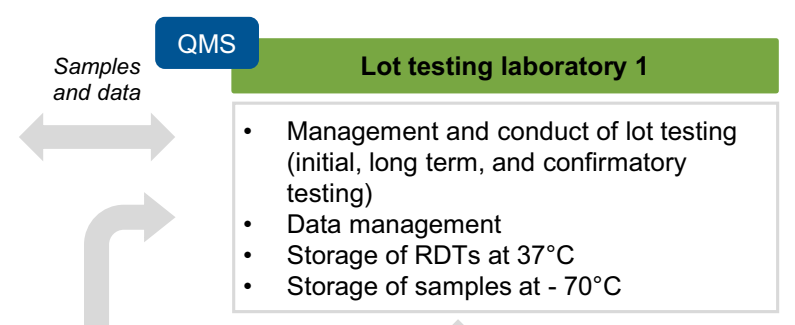

$R D T s$ and reports

QMS

\section{Lot testing laboratory 2}

- Same as above

Annual EQA visits by independent expert 
Table 1 Summary of Lot Testing failures (2007-2017)

\begin{tabular}{|c|c|c|}
\hline Reasons for lot failure & $\mathrm{Nb}$ lots failed at reception (nb RDTs) & $\begin{array}{l}\text { Nb lots failed } \\
\text { after long-term storage } \\
\text { (nb RDTs) }\end{array}$ \\
\hline Non-detection of Pv at $200 \mathrm{p} / \mu \mathrm{l}$ & $20(5.7 \mathrm{M})$ & $18(5.1 \mathrm{M})$ \\
\hline Non-detection of Pf and Pv at $200 \mathrm{p} / \mu \mathrm{l}$ & 0 & $1(0.3 \mathrm{M})$ \\
\hline Insufficient buffer ${ }^{a}$ & $6(1.7 \mathrm{M})$ & $24(6.8 \mathrm{M})$ \\
\hline Total & $26(7.4 M)$ & $43(12.2 \mathrm{M})$ \\
\hline
\end{tabular}

The numbers of lot failures and -in brackets-the corresponding estimate of numbers of RDTs (based on a mean lot size of 283,053 RDTs per lot, as communicated by LT requesters from 2013 to 2017) are shown for different reasons of failed testing (i.e. confirmed negative test results with $P$. falciparum (Pf) and $P$. vivax (Pv) samples standardized at a density of 200 parasites per microlitre of blood $(\mathrm{p} / \mu \mathrm{l})$, which were either observed upon reception of the RDT lot or after long-term storage $\mathrm{Nb}$ number, $M$ million

a Counted as a failure only from June 2016 onwards

established mechanism to ensure continued adherence to good manufacturing practice and PMS after a product is prequalified. Furthermore, it is the responsibility of the NMCPs and National Regulatory Authorities (NRAs) to perform PMS, but the processes are poorly defined or essentially non-existent in most low resource countries $[14,15]$.

India and Nigeria have established their own LT systems through collaborations with the WHO/GMP and FIND, respectively, using samples prepared locally as per the publicly available WHO-FIND procedures [20]. Other countries may adopt such a system, however the running costs, the complexity of preparing and characterizing QC samples and ensuring laboratory certification represent a considerable investment in light of the infrequent testing need of a single country. QC samples for RDTs need to have known antigen concentrations but validated antigen quantification methods are not routinely available in endemic countries. From the manufacturer's or RDT procurer's point of view, it may be challenging to deal with different laboratories and turnover times for individual countries. This does not obviate the importance of more country ownership and building efficient capacity at country or regional level to manage product quality-including post-distribution quality monitoring-across not just malaria diagnostics but those for other diseases. However, this capacity has to be matched against overall programme costs, and the ability to verify quality of the testing process and site.

The WHO-FIND system used instead an international network of reference laboratories with centralized sample characterization (Fig. 1) and is the only example of a centralized, internationally-recognized LT programme for diagnostics. The main challenges faced, e.g. developing and confirming samples of known reactivity, adapting sample collection sites and periods to changing malaria epidemiology, or facing low sample outputs within the required antigen concentration ranges, were easier to absorb with the centralized mechanism than it would have been for a country-specific programme with limited funding.

Financially, the centralized LT programme is probably the most cost-effective investment. Based on expenses incurred for the 2014-2016 period, the mean cost per lot tested has been estimated to US\$ 255 (Table 2). With approximately 700 lots tested per year, this translates to an annual cost of around \$US 178,500 in a market of over 400 million tests and an estimated budget of 120 million USD annually $[21,22]$. This seems a small price to pay to prevent incorrect diagnoses with poor quality RDTs, and to maintain confidence in RDT results.

\section{Building a framework for RDT quality control}

The LT programme is only one part of an intervention framework that ensures RDT quality. Ideally, the NRAs and NMCPs should implement and support proactive and reactive PMS activities with adequate capacity and funding, for which major donors can play a crucial role.

\section{Table 2 Estimation of costs for Lot Testing (2014-2016)}

\begin{tabular}{ll}
\hline Cost estimate (US\$) & Description \\
\hline $375,487.08$ & LT functioning $^{1}$ \\
$31,341.43$ & QC sample collections ${ }^{2}$ \\
$39,043.74$ & Characterization of samples \\
$197,425.20$ & Personnel \\
$19,117.33$ & Operational costs \\
$662,414.79$ & Total costs 2014-2016 \\
254.48 & Costs per lot ${ }^{3}$ \\
\hline
\end{tabular}

Costs for LT were estimated based on expenses incurred by the Global RDT Evaluation Programme from 2014 to 2016 , by extracting payments specifically done for LT-related activities

1 Budgets for LT work in the WHO-FIND reference laboratories, procurement of materials for LT, etc

2 Prorata of overall Programme's costs for QC samples based on percentage of samples used for LT

3 Based on 2603 lots tested throughout 2014-2016 
Table 3 List of available resource to support the PMS and correct use of malaria RDTs

\begin{tabular}{|c|c|c|}
\hline Type of resource & Resource & Access \\
\hline Guidance & Post-market surveillance of in vitro diagnostics & $\begin{array}{l}\text { https://apps.who.int/iris/bitstream/handle/10665/255576/97892 } \\
\text { 41509213-eng.pdf;jsessionid = E93138DC88FDD4ABD2D2 } \\
\text { 15B6406002AB? sequence }=1\end{array}$ \\
\hline SOP & $\begin{array}{l}\text { Methods manual for laboratory quality control testing of } \\
\text { malaria RDTs }\end{array}$ & $\begin{array}{l}\text { https://www.who.int/malaria/publications/rdt-lab-quality-manua } \\
\text { l/en/ }\end{array}$ \\
\hline SOP & Protocol on responding to problems with malaria RDTs & $\begin{array}{l}\text { https://www.finddx.org/wp-content/uploads/2016/10/Malar } \\
\text { ia-RDT-protocol-24JUN16-FINAL.pdf }\end{array}$ \\
\hline Guide & $\begin{array}{l}\text { Troubleshooting guide for supervisors overseeing users of } \\
\text { malaria RDTs }\end{array}$ & $\begin{array}{l}\text { https://www.finddx.org/wp-content/uploads/2016/10/RDT-super } \\
\text { visors-guide-2016.pdf }\end{array}$ \\
\hline Form & $\begin{array}{l}\text { User complaint form for reporting problems and/or adverse } \\
\text { events related to diagnostic products }\end{array}$ & $\begin{array}{l}\text { http://www.who.int/diagnostics_laboratory/procurement/11112 } \\
\text { 1_user_complaint_form_for_adverse_events_and_produ } \\
\text { ct_problems_reporting_english.pdf?ua=1 }\end{array}$ \\
\hline Ref material & Plasmodium falciparum antigens (1st International Standard) & $\begin{array}{l}\text { https://www.nibsc.org/products/brm_product_catalogue/detai } \\
\text { I_page.aspx?catid=16/376 }\end{array}$ \\
\hline Ref material & Plasmodium falciparum culture-derived panels & $\begin{array}{l}\text { https://www.zeptometrix.com/categories/assay-developers/ } \\
\text { microorganisms filtered by "malaria" }\end{array}$ \\
\hline Ref material & $\begin{array}{l}\text { Plasmodium falciparum and P. vivax recombinant antigens } \\
\text { (HRP2, pLDH, aldolase) }\end{array}$ & $\begin{array}{l}\text { https://www.microcoat.de/Products/malaria-reference-mater } \\
\text { ials-p-falciparum-hrp-2-recombinant/ } \\
\text { https://spandiag.com/recombinant-antigens-for-diagnostics/ }\end{array}$ \\
\hline Training material & $\begin{array}{l}\text { Training manuals, job aids, results guides, quizzes and answer } \\
\text { keys: available as generic versions for P. falciparum-only, Pf- } \\
\text { pan and pan-Pf RDTs, and as RDT product-specific versions. }\end{array}$ & $\begin{array}{l}\text { https://www.finddx.org/reports-and-landscapes/guides-manua } \\
\text { Is-implementation-tools-for-malaria-rdts/ } \\
\text { https://www.who.int/malaria/areas/diagnosis/rapid-diagnostic } \\
\text {-tests/job-aids/en/ }\end{array}$ \\
\hline
\end{tabular}

SOP Standard Operating Procedure, Ref material Reference material

A number of useful resources are publicly available (Table 3), such as the WHO guidelines for PMS of IVDs [9], a troubleshooting guide for frequently observed anomalies and errors [23], and a protocol to help setting up a process for detecting, investigating, and acting upon quality issues [24]. Training manuals, videos, job aids and quizzes have been developed by the WHO, some with extensive field testing in Zambia [25-27]. Reference materials also exist, including panels of culture-derived P. falciparum parasites [28], international standards [29], or HRP2, pLDH and aldolase recombinant proteins [30, 31 ], to be used as such or to develop secondary reference materials. These well characterized, easy to handle and temperature-stable materials may be used in complement to LT with patient-derived samples, e.g. for cross-checking RDTs withdrawn from the field, however standard procedures for their use need to be developed and widely accepted. Panels of pre-diluted recombinant proteins have been evaluated with national reference laboratories and found easy to use for RDT QC (FIND, unpublished work).

\section{Conclusions}

The WHO strategy is to make RDTs available as close as possible to patients. The tests are often used at community level and results are not confirmed a posteriori, as for tuberculosis or HIV. Total confidence in test results and quality of tests is, therefore, essential. Although tools exist for development of country-level LT, it is unrealistic to expect well-functioning processes to be in place in a near or medium-term in most endemic countries. Regional level capacity may be within reach, but first requires a concerted effort to fund inter-country mechanisms to support it. While the WHO has discussed options for continuation of the programme with key stakeholders, there remains a lack of engagement, heightening the risk of a drop in quality. Continuation of the centralized LT programme would represent a low-cost investment, while in the meantime countries and donors should invest more efforts to develop national or regional capacity. Any form of LT would significantly enhance the overall safeguarding framework, including national regulations and WHO prequalification, to help sustaining the high quality of RDTs.

\footnotetext{
Abbreviation

EQA: External quality assessment; FIND: Foundation for innovative new diagnostics; GF: The Global Fund to fight AIDS, Tuberculosis and Malaria; GMP: Global malaria programme; HIV: Human immunodeficiency virus; HRP2: Histidine rich protein 2; IPC: Institut Pasteur du Cambodge; IVD: In-vitro diagnostics; LT: Lot testing; RDT: Malaria rapid diagnostic test; MSF: Médecins Sans Frontières; NMCP: National malaria control programme; NRA: National regulatory authority; pLDH: Plasmodium lactate deshydrogenase; PMI: United States President's Malaria Initiative; PMS: Post-marketing surveillance; PQ: Prequalification of diagnostics; PT: Product testing; RITM: Research institute for tropical medicine; QC: Quality control; QMS: Quality management system; SOP: Standard operating procedures; UNICEF: United Nations International Children's Emergency Fund; WHO: World Health Organization.
} 


\section{Acknowledgements}

The authors wish to acknowledge all staff from the IPC and RITM laboratories who have contributed to the RDT Lot Testing activities, and all staff from WHO and FIND who have contributed to their coordination. Editorial assistance for later drafts of the manuscript was provided by Rachel Wright, PhD, funded by FIND, according to Good Publication Practice guidelines.

\section{Authors' contributions}

SD, SI and XCD conceived the synopsis of the publication. AC drafted the first draft of the manuscript and SD, SI and XCD developed the final draft. JC, FA, TF, $J \mathrm{~L}, \mathrm{CAL}, \mathrm{DM}, \mathrm{SN}, \mathrm{JBS}$ and BW contributed to the lot testing activities, coordination and data. All co-authors contributed to the final draft and reviewed. All authors read and approved the final manuscript.

\section{Funding}

Our work on malaria and specifically RDT quality systems was enabled by grants from the Bill and Melinda Gates Foundation, the Global Fund to fight AIDS, Tuberculosis and Malaria, the United States President's Malaria Initiative (via the United States Agency for International Development) and UNITAID, as well as funding from the Department of Foreign Affairs and Trade of the Australian government. Publication of this article was funded by FIND.

\section{Availability of data and materials}

Not applicable.

\section{Ethical approval and consent to participate}

Not applicable.

\section{Consent for publication}

Not applicable.

\section{Competing interests}

The authors declare that they have no competing interests.

\section{Author details}

${ }^{1}$ FIND, Geneva, Switzerland. ${ }^{2}$ Independent consultant, Issaquah, WA, USA.

${ }^{3}$ World Health Organization/Global Malaria Programme (WHO/GMP), Geneva, Switzerland. ${ }^{4}$ Hôpital Cochin, Laboratoire de Parasitologie-Mycologie, INSERM U1016 (Institut Cochin), Université de Paris, Paris, France. ${ }^{5}$ Direction Internationale, Institut Pasteur de Paris, Paris, France. ${ }^{6}$ Parasitology Department, Research Institute for Tropical Medicine, Muntinlupa, Philippines. ${ }^{7}$ Malaria Genetics and Resistance Unit, Parasites and Insect Vectors Department, Institut Pasteur, Paris, France. ${ }^{8}$ National Center for Entomology, Parasitology and Malaria Control, Phnom Penh, Cambodia. ${ }^{9}$ Epidemiology and Biostatistics Department, Research Institute for Tropical Medicine, Muntinlupa, Philippines. ${ }^{10}$ Laboratoire d'Epidémiologie Moléculaire du Paludisme, Institut Pasteur du Cambodge, Phnom Penh, Cambodia. ${ }^{11}$ Nuffield School of Medicine, University of Oxford, Oxford, UK.

Received: 5 March 2020 Accepted: 7 July 2020

Published online: 13 July 2020

\section{References}

1. Bell D, Wongsrichanalai C, Barnwell JW. Ensuring quality and access for malaria diagnosis: how can it be achieved? Nat Rev Microbiol. 2006:4:682-95.

2. Mouatcho JC, Goldring JP. Malaria rapid diagnostic tests: challenges and prospects. J Med Microbiol. 2013;62:1491-505.

3. Wongsrichanalai C, Barcus MJ, Muth S, Sutamihardja A, Wernsdorfer WH. A review of malaria diagnostic tools: microscopy and rapid diagnostic test (RDT). Am J Trop Med Hyg. 2007;77:119-27.

4. WHO. WHO-FIND malaria RDT evaluation programme. Geneva, World Health Organization, 2017. https://www.who.int/malaria/areas/diagnosis/ rapid-diagnostic-tests/rdt-evaluation-programme/en/. Accessed 17 Feb 2020

5. Cunningham J, Jones S, Gatton ML, Barnwell JW, Cheng Q, Chiodini PL, et al. A review of the $\mathrm{WHO}$ malaria rapid diagnostic test product testing programme (2008-2018): performance, procurement and policy. Malar J. 2019;18:387.
6. Lot testing. WHO: Geneva. https://www.who.int/malaria/areas/diagnosis/ rapid-diagnostic-tests/lot-testing/en/. Accessed 17 Feb 2020.

7. WHO. Changes to the WHO-FIND Malaria RDT Lot Testing Programme Geneva: World Health Organization. 2017. https://www.who.int/malaria/ news/2017/rdt-lot-testing/en/. Accessed 18 Feb 2020.

8. The global fund. global fund quality assurance policy for diagnostics products (Issued on 14 December 2010, most recently amended on 4 May 2017). Geneva: World Health Organization. 2017. https://www.thegl obalfund.org/media/5885/psm_qadiagnostics_policy_en.pdf?u=63660 7536980000000. Accessed 17 Feb 2020.

9. WHO. Post-market surveillance of in vitro diagnostics. Geneva: World Health Organization. 2015. https://apps.who.int/iris/bitstream/handl e/10665/255576/9789241509213-eng.pdf;jsessionid=E93138DC88 FDD4ABD2D215B6406002AB?sequence =1. Accessed 19 Feb 2020

10. WHO. Results of the FIND-WHO Lot Testing Programme for Malaria Rapid Diagnostic Tests (RDTs). Geneva: World Health Organization. 2017. https:// www.finddx.org/wp-content/uploads/2017/08/Malaria-lot-testing-resul ts-2007-endJune-2017_30AUG17.pdf. Accessed 18 Feb 2020.

11. UNITAID. Malaria Diagnostics Technology and Market Landscape, 3rd Edn. Geneva: World Health Organization. 2016. https://www.ghdonline.org/ uploads/Unitaid-Malaria-Dx-Tech-Mkt-Landscape-3rd-Ed-April-2016.pdf. Accessed 18 Feb 2020.

12. Harvey SA, Incardona S, Martin N, Lussiana C, Streat E, Dolan S, et al. Quality issues with malaria rapid diagnostic test accessories and buffer packaging: findings from a 5-country private sector project in Africa. Malar J. 2017;16:160.

13. WHO. WHO Information Notice for Users, 2016/01, version 8. Geneva: World Health Organization. 2016. https://www.who.int/diagnostics_labor atory/procurement/160429_single_buffer_ampulla_information_notic e_for_users_v8.pdf?ua=1. Accessed 19 Feb 2020.

14. McNerney R, Sollis K, Peeling RW. Improving access to new diagnostics through harmonised regulation: priorities for action. Afr J Lab Med. 2014:3:123.

15. Rugera SP, McNerney R, Poon AK, Akimana G, Mariki RF, Kajumbula H, et al. Regulation of medical diagnostics and medical devices in the East African community partner states. BMC Health Serv Res. 2014;14:524.

16. FIND. Guide for the interpretation of observations noted during lot testing of malaria RDTs. Geneva: Foundation for Innovative New Diagnostics. 2013. https://www.finddx.org/wp-content/uploads/2016/02/malar ia rdt guide for observations 30jul13.pdf. Accessed 19 Feb 2020.

17. Berhane A, Anderson K, Mihreteab S, Gresty K, Rogier E, Mohamed S, et al Major threat to malaria control programs by Plasmodium falciparum lacking histidine-rich protein 2 Eritrea. Emerg Infect Dis. 2018;24:462-70.

18. Incardona S, Serra-Casas E, Champouillon N, Nsanzabana C, Cunningham J, Gonzalez IJ. Global survey of malaria rapid diagnostic test (RDT) sales, procurement and lot verification practices: assessing the use of the WHO-FIND Malaria RDT evaluation programme (2011-2014). Malar J. 2017;16:196.

19. WHO. Prequalification of in vitro diagnostics. Geneva: World Health Organization. https://www.who.int/diagnostics_laboratory/evaluations/ en/. Accessed 19 Feb 2020

20. WHO, FIND. methods manual for laboratory quality control testing of malaria rapid diagnostic tests. Version 8. Geneva: World Health Organization and Foundation for Innovative New Diagnostics. 2016. https://www. who.int/malaria/publications/rdt-lab-quality-manual/en/. Accessed 19 Feb 2020.

21. WHO. World Malaria Report 2019. Geneva: World Health Organization. 2019. https://www.who.int/malaria/publications/world-malaria-repor $\mathrm{t}$-2019/en/. Accessed 04 June 2020.

22. UNITAID. The state of the malaria RDT market 2018, Geneva, Switzerland, 2018. https://unitaid.org/assets/The-state-of-the-malaria-RDT-marke t-2018.pdf. Accessed 04 June 2020.

23. FIND, Johns Hopkins School of Public Health, Malaria Consortium, Population Services International and WHO. Troubleshooting guide for supervisors overseeing users of malaria RDTs. Geneva, Switzerland, 2015. https://www.finddx.org/wp-content/uploads/2016/10/RDT-supervisor s-guide-2016.pdf. Accessed 19 Feb 2020.

24. FIND. Protocol on responding to problems with malaria RDTs. Geneva, Foundation for Innovative New Diagnostics, 2016. https://www.findd x.org/wp-content/uploads/2016/10/Malaria-RDT-protocol-24JUN 16-FINAL.pdf. Accessed 19 Feb 2020 
25. WHO. Training materials for use of malaria and G6PD RDTs. Geneva: World Health Organization. https://www.who.int/malaria/areas/diagnosis/rapid -diagnostic-tests/job-aids/en/. Accessed 19 Feb 2020.

26. Harvey SA, Jennings L, Chinyama M, Masaninga F, Mulholland K, Bell DR. Improving community health worker use of malaria rapid diagnostic tests in Zambia: package instructions, job aid and job aid-plus-training. Malar J. 2008;7:160.

27. FIND. Guides, manuals and implementation tools for malaria rapid diagnostic tests. Geneva: Foundation for Innovative New Diagnostics. https:// www.finddx.org/reports-and-landscapes/guides-manuals-implementa tion-tools-for-malaria-rdts/. Accessed 02 March 2020.

28. Zeptometrix Corporation. Malaria P. falciparum culture panels. New York. https://www.zeptometrix.com/categories/assay-developers/microorgan isms. Accessed 19 Feb 2020.

29. National Institute for Biological Standards and Controls (NIBSC). Plasmodium falciparum antigens (1st International Standard). South Mimms, UK. https://www.nibsc.org/products/brm_product_catalogue/detail_page. aspx?catid=16/376. Accessed 19 Feb 2020.

30. Microcoat Biotechnologie $\mathrm{GmbH}$. Malaria reference materials: P. falciparum HRP-2, recombinant. Bernried am Starnberger See, Germany. https ://www.microcoat.de/Products/malaria-reference-materials-p-falciparum -hrp-2-recombinant/. Accessed 27 Feb 2020.

31. SPAN Diagnostics SARL. Recombinant antigens for Diagnostics. Malaria: Plasmodium Aldolase (P. falciparum); pLDH (P. falciparum); pLDH (P. vivax); pHRP(II) (P. falciparum). https://spandiag.com/recombinant-antigens-fordiagnostics/. Accessed 27 Feb 2020.

\section{Publisher's Note}

Springer Nature remains neutral with regard to jurisdictional claims in published maps and institutional affiliations.
Ready to submit your research? Choose BMC and benefit from:

- fast, convenient online submission

- thorough peer review by experienced researchers in your field

- rapid publication on acceptance

- support for research data, including large and complex data types

- gold Open Access which fosters wider collaboration and increased citations

- maximum visibility for your research: over $100 \mathrm{M}$ website views per year

At BMC, research is always in progress.

Learn more biomedcentral.com/submissions 